\title{
Economic Valuation for Cost-Benefit Analysis of Health Risk Reduction in Drinking Water Systems
}

\author{
Viktor Bergion $^{1}$ (D) Andreas Lindhe ${ }^{1}$ (D) Ekaterina Sokolova ${ }^{1}$ (D) Lars Rosén $^{1}$ (D)
}

Received: 12 September 2018 / Revised: 7 December 2018 / Accepted: 10 December 2018 / Published online: 20 December 2018 (c) The Author(s) 2018

\begin{abstract}
Microbial risk mitigation measures in drinking water systems aiming at preventing gastrointestinal disease can provide substantial societal health benefits if implemented properly. However, the procedure of including and monetising the health benefits in cost-benefit analysis (CBA) has been somewhat scattered and inconsistent in the literature, and there is a need for a comparison of available methods. First, through a literature review, we identified the methods to include health benefits in decision support and to monetise these benefits in CBA. Second, we applied the identified health valuation methods in a case study. In the case study, we investigated if changing the health valuation method could change the rank order of the decision alternatives' net present values. In the case study a risk-based decision model that combined quantitative microbial risk assessment and CBA was used. Seven health valuation methods were identified, each of them including different aspects of health benefits. The results of the case study showed that the choice of the health valuation method can change the rank order of decision alternatives with respect to their net present values. These results highlight the importance of choosing an appropriate health valuation method for the specific application. Although this study focused on the drinking water context, the identified health valuation methods can be applied in any decision support context, provided that input in terms of the health risk reduction is available.
\end{abstract}

Keywords Decision support · Health benefits · Microbial risk · Quality adjusted life year (QALY) - Quantitative microbial risk assessment (QMRA) · Risk mitigation

\section{Introduction}

To improve society and human health, the United Nations has adopted 17 sustainable development goals, of which several concern water and sanitation related to gastrointestinal disease. Gastrointestinal disease is one of the major causes of negative health effects globally (WHO 2008). In Sweden, several large waterborne outbreaks of gastrointestinal disease have taken place during the last decades (PHAS 2011) causing substantial costs to society (Lindberg et al. 2011). Hence, mitigation of microbial health risks in order to avoid gastrointestinal disease is of value to society. Risk management is also essential for water utilities to provide safe drinking water. Cost-benefit analysis (CBA), increasingly applied to support decision makers, is one aid to help maximise risk

Viktor Bergion

viktor.bergion@chalmers.se

1 Department of Architecture and Civil Engineering, Chalmers University of Technology, 41296 Gothenburg, Sweden reduction when allocating scarce societal resources. However, the procedures for monetising and including health benefits in CBA have been somewhat scattered and inconsistent. There is a need for a comparison of different health valuation methods. In this paper, we identify and compare methods for valuation of health benefits in the context of microbial health risk reduction in drinking water systems. We also apply the identified methods in a case study to illustrate their effects on decision support.

Societal resources are limited, and it is important to use adequate decision support when choosing the risk mitigation measures to implement. In our earlier study (Bergion et al. 2018), a decision model was developed to facilitate the comparison and evaluation of microbial health risk reduction measures in drinking water systems. The decision model combines quantitative microbial risk assessment (QMRA) and CBA. Through combining these two methods, societal benefits from health risk reduction measures can be included in decision support in a structured and transparent manner. QMRA (Haas et al. 2014) is an established concept 
for estimating microbial risk and has been applied to drinking water systems (e.g. Schijven et al. 2011; WHO 2016). In the decision model (Bergion et al. 2018), the health risk reductions are quantified using QMRA. In the CBA, these health risk reductions are monetised into health benefits. The benefits are compared to the costs of the mitigation measure, using the net present value (NPV), to evaluate the societal profitability of each risk reduction measure. The NPV is the sum of discounted costs and benefits, using a social discount rate in order to account for time preferences and productivity of capital (Hanley and Barbier 2009). The NPV can also be used to compare different risk reduction measures with each other. Adopting a CBA perspective provides a societal perspective by also including external effects (e.g. environmental costs).

Different aspects of health benefits related to environmental decision making are illustrated in Fig. 1. The horizontal cells in Fig. 1 divide the health benefits into the following aspects: cost of illness in terms of medical costs; cost of illness due to loss of production; cost of averting behaviour (costs that occur due to investments or behaviour that aims for avoiding risks) and intangible costs (costs that relate to effects that are not possible to monetise due to the absence of a market value). The vertical cells in Fig. 1 divide the aspects between costs that are borne by the society and costs that are borne by individuals. This division of aspects facilitates comparison and helps map the different health valuation methods, since the cells that are included in each health valuation method differ.

In a risk management framework, one approach to quantify health risk reduction is through the probability of illness. Several states of illness can be described. In a drinking water context focusing on pathogens causing gastrointestinal disease, these states of illness can be divided into mild cases (watery diarrhoea/loose stool, nausea and acute vomiting, intestinal cramps), severe cases (visits to physician, hospitalisation), secondary (sequelae) conditions (irritable bowel syndrome, Guillain-Barré syndrome, reactive arthritis, etc.) and deaths (Rice et al. 2006). Another approach to quantify health risk reduction is through health adjusted life years (HALYs). HALYs are health metrics, e.g. disability adjusted life years (DALYs) and quality adjusted life years (QALYs), that include both the severity of the illness accounting for all possible states of illnesses, including death, and the duration of the illness, into one single metric. DALYs combine the life years lived with disability and the years of life lost. QALYs can in general terms be described as the inverse of DALYs (1 DALY $\approx-1$ QALY), but instead of measuring disability, QALYs estimate the quality of life. The value of health risk reduction in, for example, water resource management can be estimated through economic valuation (Andersson et al. 2016; Birol et al. 2006). The economic valuation can be performed using willingness to pay (WTP) studies, such as stated preferences (e.g. contingent valuation methods, choice experiment) and revealed preferences (e.g. cost of illness (COI), averted expenditure).

Hofstetter and Hammitt (2002) described WTP, DALYs and QALYs as health metrics for environmental decision support. However, the different metrics include different cells in Fig. 1. Moreover, the WTP is a monetised metric, whereas the DALYs and QALYs have not initially been monetised. For example, the WTP includes all the private costs, whereas the DALYs and QALYs cover only the individual borne intangible costs (Fig. 1) (Hofstetter and Hammitt 2002). Hence, it is of great importance to be aware of the included health benefit aspects and of the impact that the choice of health valuation method has on CBA as decision support.

The specific aims of this paper were to: identify health valuation methods related to gastrointestinal illnesses; map the health valuation methods in relation to the health benefit aspects presented in Fig. 1 and to assess the effect
Fig. 1 Avoided costs related to health benefits relevant for environmental decision making, adopted and adjusted from Seethaler (1999) and Hofstetter and Hammitt (2002). Note that from a risk management perspective, these costs are in fact benefits when the health risks are reduced

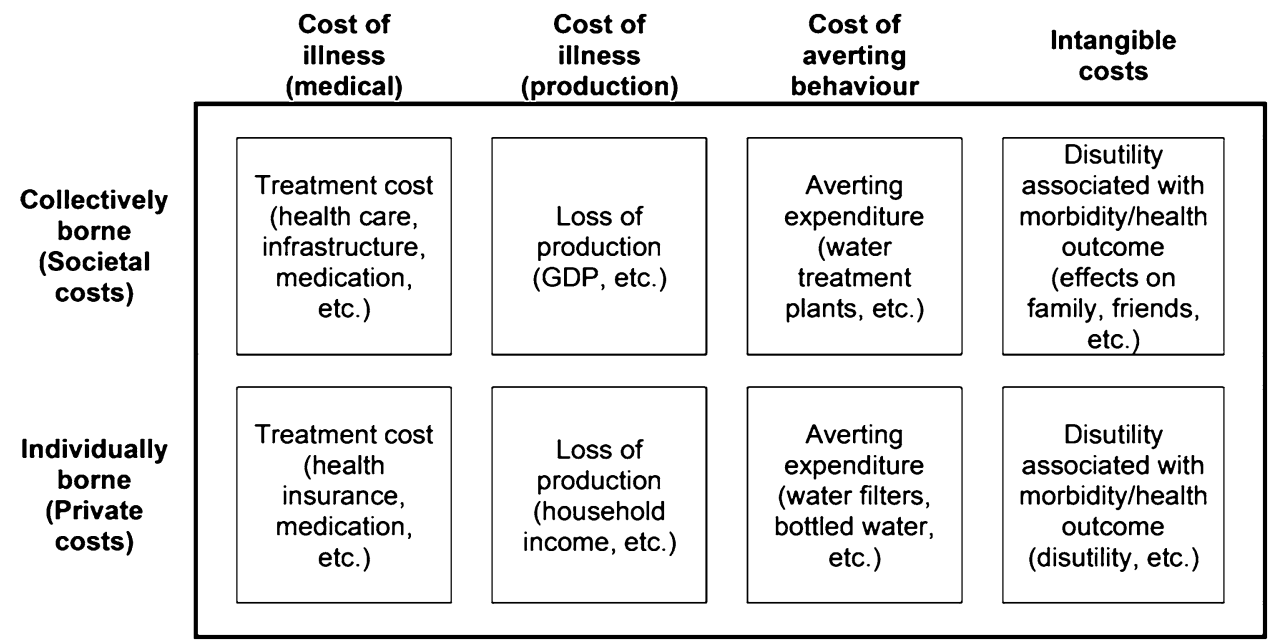


of different health valuation methods when applied in CBA as decision support for microbial risk mitigation measures in a drinking water system. More precisely, in a case study, we investigated if changing the health valuation method could change the rank order of the decision alternatives' NPVs. It should be noted that the intention of this paper was not to fully review all health valuation methods, but rather to illustrate and describe a wide range of methods that are available for monetising health benefits to provide input for CBA.

\section{Methods}

First, a literature review was performed to identify methods for economic valuation of gastrointestinal illness. Second, the identified methods were applied in a case study using a risk-based decision model to prioritise microbial risk mitigation measures in a drinking water system. The case study is reported in a separate chapter.

The literature review of health valuation methods was conducted using an approach suggested by Gyllensvärd (2010), although adjusted to be suitable for a method review. The strategy was to identify literature that: estimated the WTP for avoiding gastrointestinal/foodborne disease/illness; applied COI approaches in CBA studies; estimated the monetary value of a DALY/QALY; estimated the societal monetary value of a DALY/QALY; or provided/applied other type of health valuation methods in the context of CBA. Scopus and Web of Science Core Collection were primarily used for acquiring references.

Various combinations of the words/strings were used: "economic valuation", "stated preferences", "revealed preferences", "cost of illness", "health effects", "quality adjusted life years", "disability adjusted life years", "gastrointestinal disease", "foodborne illness", "pathogen", "water quality", "drinking water quality", "microbial water quality", "decision support", "decision making", "decision model", "cost-benefit analysis" and "benefit-cost-analysis". Additionally, reference lists in relevant literature were scrutinised to acquire more information.

Inclusion criteria were that the study provided either a clear description of the health benefits included in the CBA or that the health benefits were monetised. In total, 84 studies were listed and graded using the scale relevant, possibly relevant and irrelevant. When a health valuation method was identified, further search strings for that specific method were used. In this expanded search, also grey literature was considered. Studies related to air pollution were excluded since the focus was on waterborne gastrointestinal illnesses.

\section{Results}

In this section, we first list the identified health valuation methods (Table 1) and relate them to the health benefit aspects described in Fig. 1. We then describe each method and relate it to CBA and the different health benefit aspects in more detail. Note that the list does not claim to be complete, but rather comprises the methods that are possible to apply in a risk-based CBA and are of interest to use in the previously developed decision model (Bergion et al. 2018) for drinking water applications. Even so, the identified methods can be valid for other decision models as well.

WTP for avoiding a certain state of illness can be elicited using both stated preferences and revealed preference methods (Andersson et al. 2016; Birol et al. 2006). Choice experiments have been used for estimating the WTP for health risk reduction in water for Campylobacter (Andersson et al. 2016), and contingent valuation method and choice experiment were used for general microbial risks (Adamowicz et al. 2011). The WTP for avoiding a case of campylobacteriosis was estimated to SEK (year 2016) 490,000 (SEK 499,800, year 2017) (Andersson et al. 2016), for avoiding general microbial illness Can\$ (year 2004) 24,000-28,000 (SEK 182,160-212,520, year 2017) (Adamowicz et al. 2011), and for avoiding gastrointestinal disease US\$ (year 2012) 1752 (SEK 15,339, year 2017) (Viscusi et al. 2012).

COI of a specific pathogen can be used as a proxy for WTP (Mangen et al. 2010). COI generally includes cost for healthcare, cost for production loss and some studies also include the cost of premature fatalities in various ways (Rice et al. 2006). A recent paper summarised COI in Sweden for five foodborne pathogens; a case of campylobacteriosis was estimated to cost $€$ (year 2016) 979 (SEK 9586, year 2017) (Sundström 2018).

$\mathrm{COI}+$ includes $\mathrm{COI}$ and adds disutility using various methods. COI has been complemented with WTP (Lvovsky et al. 2000; Mangen et al. 2010) and/or QALY/ DALY (Mangen et al. 2010; Scharff 2012) to make sure that additional health benefit aspects are considered. Nevertheless, it is essential not to double count any costs (Lvovsky et al. 2000). Minor et al. (2015) reported the average cost of foodborne illness to be US\$ (year 2013) 3630 (SEK 31,781, year 2017) per case in the United States; the analysis included all aspects of COI and also accounted for disutility of being ill by monetising a QALY. Hoffmann et al. (2012) included premature death estimate in their COI for different foodborne illness, using a value of a statistical life. In Sweden, a CBA was performed for investing in ultrafiltration treatment for increased drinking water quality; the health benefits were accounted for using a $\mathrm{COI}+$ approach including medical and production 
Table 1 Description of the identified health valuation methods

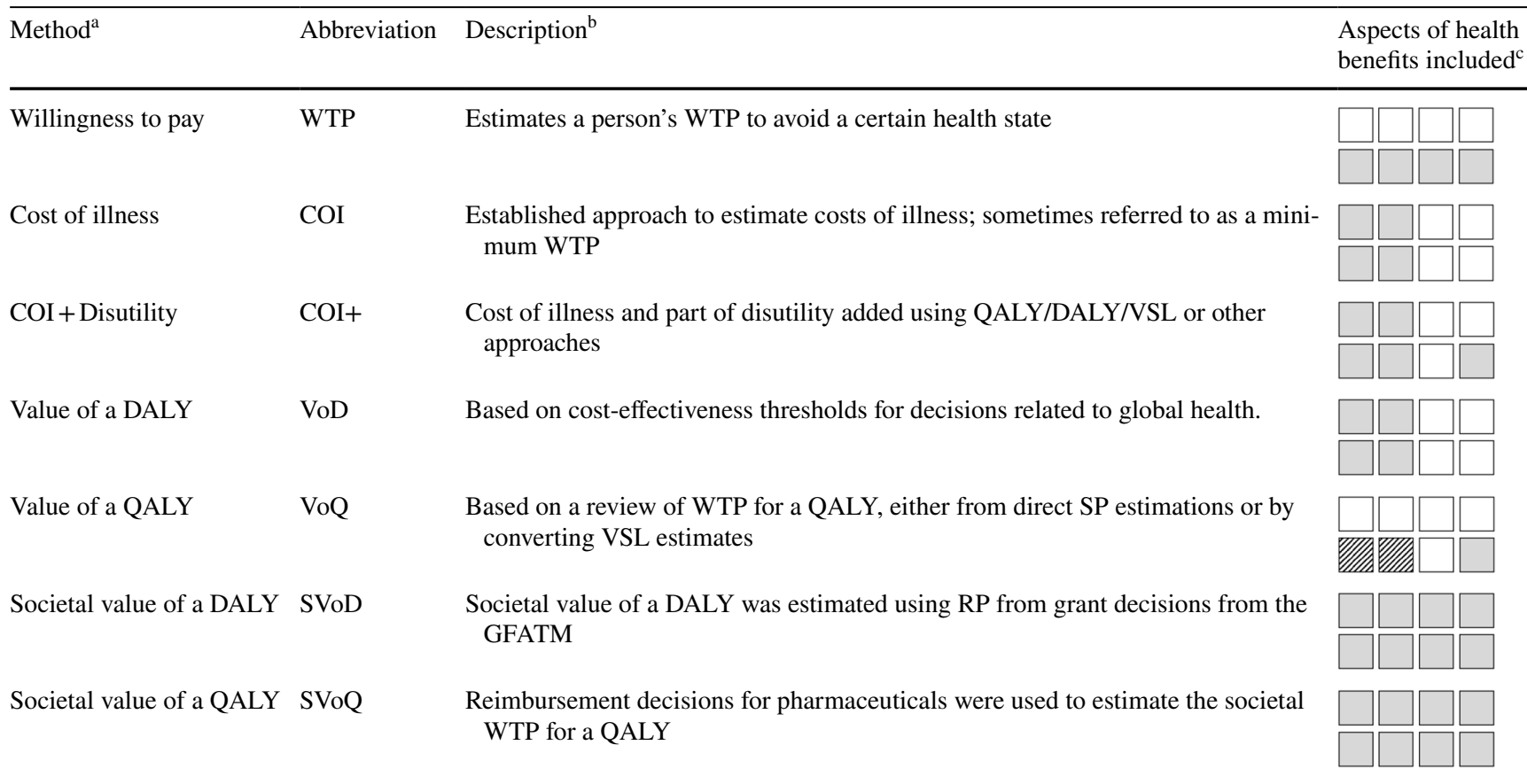

The illustrations in the rightmost column refer to the different aspects of health benefits described in Fig. 1

${ }^{a}$ Examples of references that describe or use the methods: WTP (Andersson et al. 2016); COI (Scharff 2012; Sundström 2018); COI+(Minor et al. 2015; Scharff 2012); VoD (Robinson et al. 2016; WHO 2001); VoQ (Ryen and Svensson 2015); SVoD (Brent 2011); SVoQ (Svensson et al. 2015)

${ }^{\mathrm{b}}$ Quality adjusted life years (QALY), disability adjusted life years (DALY), value of a statistical life (VSL), revealed preferences (RP), stated preferences (SP) and Global Fund for AIDS, Tuberculosis and Malaria

${ }^{c}$ The boxes shaded in grey are referring to the included benefits illustrated in Fig. 1. Striped boxes indicate that the boxes can be included depending on the study forming the base of the valuation

costs of illness and adding disutility using a unit cost per day (WSP 2010). The disutility was based on findings by Ready et al. (2004).

The value of a DALY (VoD) has been estimated using, for example, human capital approach (using gross domestic product to estimate loss of production) (WHO 2001) and friction cost method (Mangen et al. 2005). Measures for health risk reduction have been assessed to be cost-effective if they result in a cost per avoided DALY of one to three times the per capita gross domestic product (Robinson et al. 2016; WHO 2001). It should be noted that estimating the VoD using the human capital approach does not include the individual borne intangible costs.

The value of a QALY (VoQ) was early described for foodborne illness by Mauskopf and French (1991); the health benefits in terms of increased QALYs were multiplied by a unit value for one QALY. Two main approaches to estimate the value of a QALY are to either elicit the WTP directly or to estimate the WTP based on value of a statistical life (Andersson et al. 2015). A recent review (Svensson et al. 2015) of literature estimating the WTP for a QALY reported a wide spectrum of QALY valuations ranging from $<€ 10,00$ to $€ 4,800,000$ (SEK 10,176-48,844,800, year 2017). The wide range is explained by the fact that each study differs in methodology, elicitation method, geography, social/individual perspective, etc. If studies are based on health metrics including aspects of loss of production, then the health benefit aspects of individual costs of illness can also be included, as indicated by the striped cells in Table 1.

The societal value of a DALY (SVoD) was estimated based on disbursement of means from the Global Fund for AIDS, Tuberculosis and Malaria (Brent 2011). These estimates can be interpreted as a revealed preference method for estimating the societal WTP for avoiding one DALY.

In the context of the societal value of a QALY (SVoQ), Bobinac et al. (2010) suggested three possible methods for estimating the threshold for cost-effective healthcare improvements: institutional decisions, budget constraints and the marginal societal value of health. For estimating the cost-effectiveness of healthcare improvements, thresholds of cost per QALY have been established in several countries. In Sweden, the National Board of Health and Welfare has provided a threshold of SEK 500,000 per QALY (NBHW 2015). Svensson et al. (2015) have suggested a high (SEK 
1,256,600, year 2017) and a low (SEK 721,000, year 2017) implied societal WTP for a QALY, based on pharmaceutical reimbursement decisions; this study states that the estimate incorporates all costs, including costs beyond the healthcare sector.

\section{Case Study}

In this section, the case study is described; more information regarding the case study and detailed description of the risk-based decision model can be found in Bergion et al. (2018). For the case study, we chose the Vomb drinking water system that provides drinking water to approximately 330,000 consumers in the south of Sweden. High density of on-site wastewater treatment systems (OWTSs), wastewater overflows and grazing animals in the catchment of the water source Lake Vomb were identified as risk sources. The case study focused on comparing alternatives for risk mitigation aimed at reducing the microbial risks. Three mitigation alternatives (A1-3) were connecting 25,50 and $75 \%$ of the OWTSs to a wastewater treatment plant that discharges the effluent to a non-drinking water recipient. A fourth mitigation alternative (A4) was installing a UV disinfection step in the drinking water treatment plant. In the risk-based decision model, hydrodynamic modelling and QMRA were used to calculate the annual number of avoided infections for each mitigation alternative. In this case study, Campylobacter, norovirus and Cryptosporidium were used as reference pathogens, representing the pathogen groups, bacteria, viruses and protozoa respectively. The avoided cases were monetised and included in a CBA to compare the mitigation alternatives. Monte Carlo simulations (10,000 iterations) were used throughout the model to include uncertainties.

Health benefits were expressed as avoided infections with each pathogen. The reduced infections $\left(R_{I}\right)$ were expressed as:

$R_{I}=P_{i} \cdot C$

where $P$ was the reduction in annual probability of infection for reference pathogen $i$ and $C$ was the number of drinking water consumers supplied with water from the Vomb drinking water treatment plant. It was conservatively assumed that all infections resulted in illness. The reduction in annual probability of infection for Campylobacter, norovirus and Cryptosporidium were calculated in our earlier study (Bergion et al. 2018) and are summarised in Table 3 in Appendix. The number of consumers was assumed to be 330,000 in the year 2016. The projected population growth of 30\% by the year 2060 (Statistics Sweden 2018b) was recalculated into an annual population growth used throughout the time horizon. The number of consumers in the end of the 100year time horizon was thus 560,000.
The health benefits were monetised using the identified health valuation methods (Table 1) for each reference pathogen. Monetary values were expressed in SEK recalculated to their value in the year 2017 (Statistics Sweden 2018c) and using the average exchange rates for 2017 of SEK 8.5, 6.6 and 9.6 for $\$$ US, $\$$ Can and $€$, respectively (Sveriges Riksbank 2018). The adopted values for different illnesses are also reported in Table 4 in the appendix. For monetising the health benefits, the general equation was:

$B_{\mathrm{H} j}=m_{j}\left(R_{I}\right)$

where $B_{\mathrm{H} j}$ was the monetary value of the health benefit, $m_{j}\left(R_{I}\right)$ was a function describing the value of avoiding an illness when using the health valuation method $j$.

For willingness to pay (WTP), the following equation was used:

$B_{\mathrm{H} \_\mathrm{WTP}}=\mathrm{WTP}_{i} \cdot R_{I}$

WTP was SEK 499,800; 29,224 and 111,420 for Campylobacter (Andersson et al. 2016), norovirus and Cryptosporidium, respectively. For norovirus and Cryptosporidium, the WTP was estimated using the WTP for avoiding Campylobacter and adjusted using the ratio of the loss of QALY between Norovirus and Campylobacter (17.4), and Cryptosporidium and Campylobacter (4.5), respectively.

For cost of illness (COI), the following equation was used:

$B_{\mathrm{H} \_\mathrm{COI}}=\mathrm{COI}_{i} \cdot R_{I}$

COI was SEK 9586; 4775 and 18,525 Campylobacter (Sundström 2018), norovirus (Scharff 2012) and Cryptosporidium (Scharff 2012), respectively.

For cost of illness + disutility $(\mathrm{COI}+D)$, the following equation was used:

$B_{\mathrm{H} \_\mathrm{COI}+D}=(\mathrm{COI}+D)_{i} \cdot R_{I}$

COI $+D$ was SEK 30,537; 6064 and 26,273 for Campylobacter (Minor et al. 2015), norovirus (Scharff 2012) and Cryptosporidium (Scharff 2012), respectively.

For value of a DALY (VoD), the following equation was used:

$B_{H_{-} \mathrm{VoD}}=\mathrm{VoD} \cdot D_{i} \cdot R_{I}$

where $D_{i}$ was the amount of DALYs gained if an illness with pathogen $i$ was avoided. VoD was the Swedish gross domestic product per capita (SEK 457,000) for the year 2017 multiplied by three (Statistics Sweden 2018a). $D_{i}$ was set to be $0.00328,0.000716$ and 0.00267 DALYs for Campylobacter, norovirus and Cryptosporidium, respectively, based on the QMRA-tool developed for Swedish drinking water producers (Abrahamsson et al. 2009).

For value of a QALY (VoQ), the following equation was used:

$B_{H_{-} \mathrm{VoQ}}=\mathrm{VoQ} \cdot Q_{i} \cdot R_{I}$ 
where $Q_{i}$ was the amount of QALYs gained if an illness with pathogen $i$ was avoided. VoQ was the mean value reported by Ryen and Svensson (2015). $Q_{i}$ was assumed to be 0.0157 , 0.0009 and 0.0035 QALYs for Campylobacter, norovirus and Cryptosporidium, respectively (Batz et al. 2014).

For societal value of a DALY (SVoD), the following equation was used:

$B_{\mathrm{H} \_\mathrm{SV}}=\mathrm{SVoD} \cdot D_{i} \cdot R_{I}$

SVoD was SEK 61,583 based on Brent (2011).

For societal value of a QALY (SVoQ), the following equation was used:

$B_{\mathrm{H} \_\mathrm{SVoQ}}=\mathrm{SVoQ} \cdot Q_{i} \cdot R_{I}$

SVoQ was SEK 1,256,600 based on the high estimate of societal WTP for a QALY reported by Svensson et al. (2015).

The environmental benefits for mitigation alternatives A1-3 were identified as reduced nutrient load to the recipient, due to increased removal of phosphorous and nitrogen in the wastewater treatment plant. For A4, no environmental benefits were identified. The total benefits $(B)$ were calculated as:

$B=B_{\mathrm{H} \_i}+B_{\mathrm{E}}$

where $B_{\mathrm{H}_{-} i}$ were the health benefits and $B_{E}$ were the environmental benefits.

The net present value (NPV) was calculated as:

$\mathrm{NPV}=\sum_{t=0}^{T} \frac{\left(B_{t}\right)}{(1+r)^{t}}-\sum_{t=0}^{T} \frac{\left(C_{t}\right)}{(1+r)^{t}}$

where $B$ and $C$ were the monetised benefits (SEK) and costs (SEK) for each year $t$ during the time horizon $T$ (years), and $r(\%)$ was the discount rate. The costs and further details regarding the environmental benefits for each mitigation alternative were presented in Bergion et al. (2018).

In Sweden, there are no guidelines on what discount rate to choose when performing a societal CBA for reducing microbial risks. In this study, a discount rate of $3.5 \%$ was chosen, as suggested by the Swedish Transport Administration when performing societal CBA for large infrastructure projects (STA 2016). For sensitivity analysis, a discount rate of $1 \%$ was applied. Using a lower discount rate in economic analyses concerning long time horizons and future generations have been extensively described (e.g. Boardman et al. 2011). A time horizon of 100 years was used. As a sensitivity analysis, a time horizon of 50 years was also included. The rank order of the mitigation alternative was calculated based on the expected NPV.

The risk reduction was expressed as avoided annual cases of illnesses with reference pathogens (Table 2) calculated by combining the reduced annual probability of infection with the number of drinking water consumers, conservatively assuming that all infections result in illness.

The total benefits for each mitigation alternative calculated using the identified health valuation methods are presented (Fig. 2).

The division of the total benefits between the health and environmental benefits varied depending on the health valuation method (Fig. 2). It is clear that the WTP method generates substantially larger benefits than the other methods.

The rank orders of the NPVs for the risk mitigation alternatives are presented in Fig. 3.

The rank order of the NPV varied depending on the health valuation method for WTP, COI and $\mathrm{COI}+$, but not for VoD, VoQ, SVoD and SVoQ (Fig. 3). A3 was the alternative with the lowest rank. A4 had the highest ranking when using WTP, indicating that when health benefits were valued at a higher level, the most societally beneficial alternative changed from A1 to A4. The rank order also varied depending on the time horizon and/or the discount rate. Going from $3.5 \%$ to $1 \%$ discount rate increased the rank of $\mathrm{A} 2$ and decreased the rank of A1 and A4 depending on which valuation method applied. Using a longer time horizon promoted A4 for the valuation methods COI and $\mathrm{COI}+$ when looking at the $1 \%$ discount rate but only for COI when looking at the $3.5 \%$ discount rate. Front loaded risk reduction measures, i.e. when investment costs occur in the beginning, get higher rank if low discount rates and long time horizons are used, since a higher value is assigned to the benefits that occur in the future relative if a higher discount rate is used. A low discount rate and a long time horizon favoured the mitigation alternative $\mathrm{A} 2$ resulting in an increase in rank order for the valuation method WTP, whereas the other mitigation

Table 2 Avoided annual cases (5th, 50th and 95th percentiles) for the reference pathogens Campylobacter (Campy), norovirus (Noro) and Cryptosporidium (Crypto) for the risk mitigation alternatives A1-4

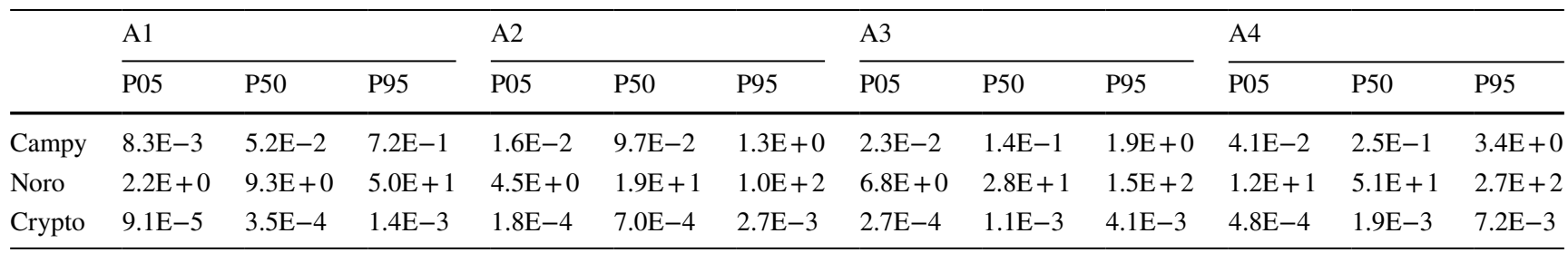


Fig. 2 Total benefits (mean value) for the risk mitigation alternatives (A1-4), using different health valuation methods (WTP, COI, COI +, VoD, VoQ, SVoD and SVoQ). The division between the health (dark grey) and environmental (light grey) benefits is illustrated. A time horizon of 100 years and a discount rate of $3.5 \%$ were used. For abbreviations see Table 1
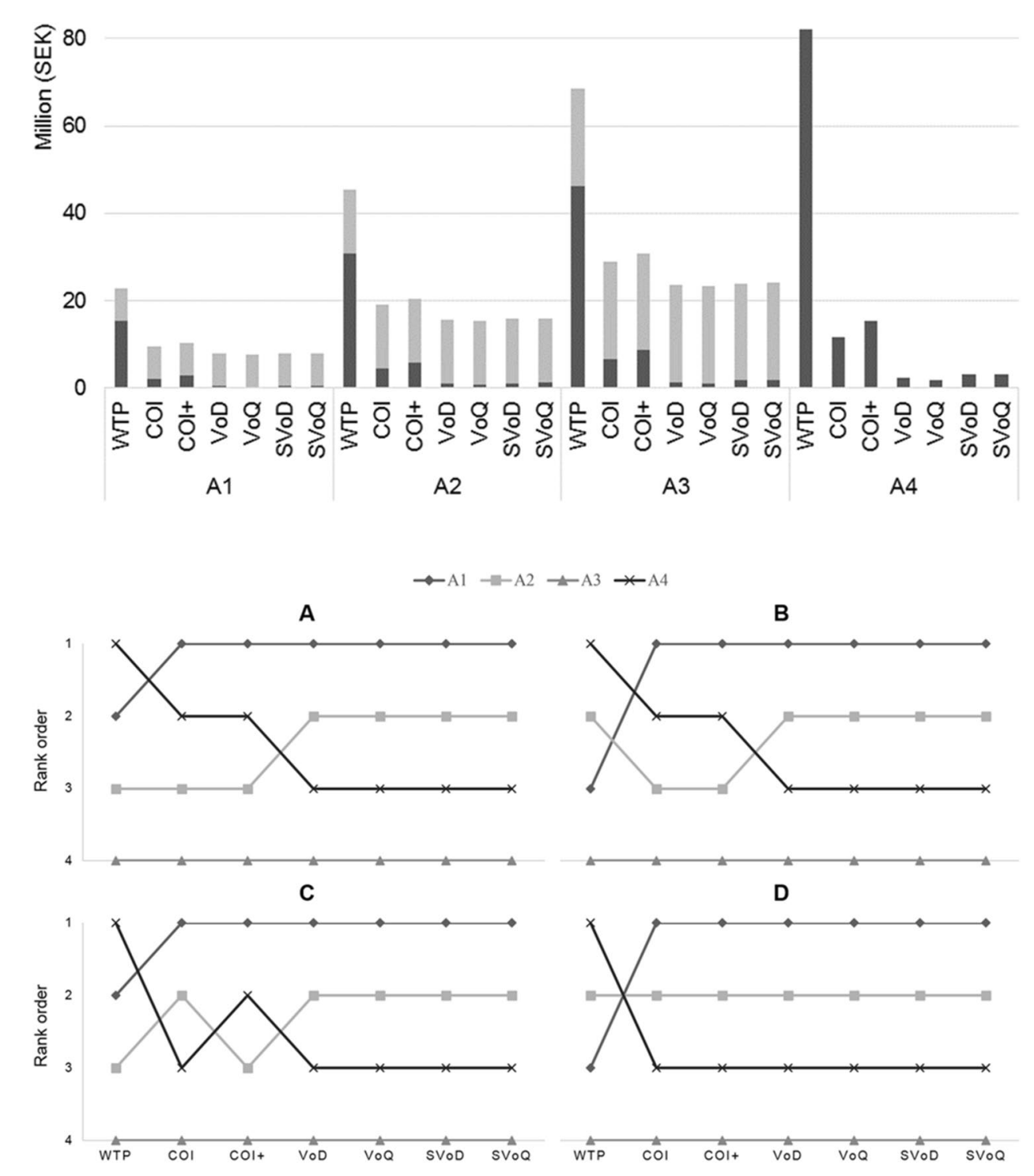

Fig. 3 Rank order of the NPVs (mean value) of the mitigation alternatives (A1-4) using different health valuation methods (WTP, COI, COI +, VoD, VoQ, SVoD and SVoQ). The results are shown for time horizons of 100 (a and $\mathbf{b})$ and 50 years (c and d) as well as discount rates of 3.5 (a and $\mathbf{c}$ ) and 1\% (b and d). For abbreviations see Table 1 alternatives kept their rank (A3) or lowered their rank (A1 and A4).

\section{Discussion}

Different methods can be used to support decisions on how to mitigate health risk in drinking water supplies. Methods such as multi criteria decision analysis and cost-effectiveness analysis do not require a monetisation of health effects. However, there are benefits of monetising health effects since it, for example, clarifies the societal benefits of implementing mitigation measures and thus provides useful decision support. The question of which health valuation method to use, is not straightforward to answer, as it depends on the purpose and the context of the decision. Mangen et al. (2010) suggested that COI + (a combination of COI and WTP, or COI and DALYs/QALYs) can be used to describe health burden when prioritising foodborne risk mitigation. Cookson (2003) saw a possibility to use WTP for resource allocation between different societal sectors (water, traffic, agriculture, etc.). The use of a societal WTP for avoiding a QALY (Svensson et al. 2015) or a DALY (Brent 2011) is another approach.

The importance of the societal aspect has been emphasised when quantifying health effects for decision making (Bobinac et al. 2013; Shiroiwa et al. 2010). Several studies of the WTP for a QALY showed that the level of WTP for your own health, family health or health in society differed (Hammitt and Haninger 2017; Shiroiwa et al. 2010). In UK, US and Australia, the WTP for societal health was higher than the WTP for improving personal health (Shiroiwa et al. 2010). This implies that the valuation of health reaches beyond the individual perspective, and it has been suggested to use a societal WTP for a QALY in economic assessments (e.g. Whitehead and Ali 2010). 
Using a SVoD or a SVoQ, from a societal point of view, includes all aspects of the health risk reduction. Adopting a societal rather than individual point of view can also account for altruistic effects (Adamowicz et al. 2011). Four issues were identified that have implications for estimating the societal value of a QALY (Smith and Richardson 2005): Is societal WTP the sum of individual's WTP?; Will individual WPT map directly to societal WTP?; Is personal income the appropriate budget constrain?; Should we adjust WTP for ability to pay?. These issues need to be recognised in order to transfer individual WTP methods for valuing QALYs into societal WTP for QALYs to be used in decision making. Nevertheless, aggregating individual WTP can be one of several possible ways to estimate the societal WTP and is closely related to a utilitarian approach (Smith and Richardson 2005). The societal WTP for avoiding a DALY would provide some kind of a lowest value of a DALY (Brent 2011). This is because there is a public consensus that not enough resources were put into preventing these diseases, and that the grants provided from the Global Fund for AIDS, Tuberculosis and Malaria were made under strict budget constraints (Brent 2011). Therefore, if more money would be available, larger investments would have been possible, and the societal WTP for a DALY would be higher.

WTP for avoiding specific health states, or for general health improvements, has been criticised, since it can be affected by individual income level and thus promoting health interventions that are targeted towards health risk reductions in wealthy parts of society (Polyzou et al. 2011; SBU 2014). From a healthcare perspective, WTP was described to be inappropriate for estimating the economic value of an intervention, since in the estimates based on contingent valuation method or choice experiments, respondents tend to be insensitive to the magnitude of health improvements and the duration of illness (Haninger and Hammitt 2011), and the valuation of the specific intervention being surveyed is exaggerated (Cookson 2003). WTP for avoiding an illness has been assessed to diminish with increasing duration of illness (Reed Johnson et al. 1997; Van Houtven et al. 2006). Increasing severity has been shown to both increase the WTP (Reed Johnson et al. 1997; Van Houtven et al. 2006) and to decrease the WTP (Cookson 2003; Haninger and Hammitt 2011). Thus, using a case specific WTP would be preferred.

Looking at the QALY value, or the WTP for avoiding a QALY, there are similar concerns as for the WTP for avoiding a specific health state. If QALY values are based on a questionnaire on prolonged life (value of a statistical life) rather than increased life quality, the QALY value will be higher (Ryen and Svensson 2015). Furthermore, studies investigating the WTP for small changes in QALYs often render a larger WTP compared to when larger changes in QALYs are investigated (Haninger and Hammitt 2011;
Ryen and Svensson 2015). Hence, the issue of "a QALY is a QALY is a QALY" (i.e. whether a QALY is the same regardless of other factors such as the cause of disease, severity, length of illness, etc.) is once again highlighted (Ryen and Svensson 2015).

In the case study, the choice of health valuation methods was shown to change the rank order of the risk mitigation alternatives. These results indicate that decision makers need to be aware of the health valuation method used and of the health benefit aspects included. When using the WTP method, alternative A4 is ranked as number one, since it was the mitigation alternative with the highest health risk reduction. The case study only included health benefits and environmental benefits, omitting any additional benefits that can be related to water quality improvements (Hutton 2001) (e.g. better productivity/products related to industry, aquaculture, agriculture; and improved animal health). The relative importance between the health and environmental benefits was shown to change depending on the health valuation method. The approach here was to include investment, maintenance and reinvestment costs. However, the reinvestment costs are only partly considered. Especially, for the UV treatment, a more comprehensive approach could be used. In this type of model, it may also be important to define terminal values since these and reinvestments may affect the outcome of the model. Hence, depending on the main reason for implementing the risk reduction measure and their characteristics, the decision makers need to be aware of the relative importance of health and environmental benefits, as well as of reinvestments and terminal values.

The results of this study promote the use of a SVoQ or SVoD when applying health valuation methods in a societal CBA for preparing decision support in a drinking water system. This is also valid in other types of contexts in which it is important to include all of the health benefit aspects. Using SVoQ or SVoD helps avoiding double counting of health benefit aspects. Nevertheless, using a unit value for a SVoQ or SVoD makes it difficult to distinguish the contribution from each aspect. If separation of different aspects is of importance, a COI or COI+ approach allows for the different aspects to be described in detail. It is also possible to use a combination of COI and $\mathrm{VoQ}$ or $\mathrm{VoD}$, but combining several methods makes it important not to double count any of the health benefit aspects.

In the study by WSP (2010) on the societal profitability of installing ultrafiltration in a drinking water treatment plant, the daily cost for disutility was based on the report (SNIER 2009), which in turn was based on Ready et al. (2004). Ready et al. (2004) performed a stated preference study of avoiding the health outcome described as "One day of persistent nausea and headache with occasional vomiting... (the) patient is unable to go to work or leave the home, but domestic chores are possible." This description indicates 
that the study participants were expected to include their loss of production in the response. It is thus unclear whether the approach by WSP (2010) double counts part of the health benefits, since the cost of illness (production) was accounted for separately, and the study (Ready et al. 2004) used for estimating the cost of disutility also could have included parts of the production loss, depending on how exactly the survey was conducted and how the respondents interpreted the health outcome description. The original questionnaires from the study by Ready et al. (2004) were not available to be scrutinised. This issue illustrates the difficulty of comparing and transferring results from stated preference studies and further emphasises the importance of being aware of the different health benefit aspects (Fig. 1).

It has been shown that it is preferred to reduce health risks related to drinking water compared to foodborne health risks, because the latter are easier to control (Andersson et al. 2016); one can choose which food to buy unlike the drinking water delivered to the tap. Additionally, if a DALY was caused by HIV or AIDS, the value of that DALY was higher compared to the other studied illnesses (Tuberculosis and Malaria) (Brent 2011). Given that the health valuation is affected by the cause of the health impairment, there is a need for further research to establish common methods for health benefit valuation, overarching different contexts and societal sectors (water, food, traffic, etc.), while at the same time acknowledging their heterogeneity. The question of how health valuation over time should be integrated into CBA needs to be addressed. One option could be to use a non-linear function to estimate the value of health. CBA facilitates the inclusion of health benefits as part of a holistic decision support, in which other, non-health, effects (e.g. supply interruption, aesthetic benefits) can also be included. Thus, CBA helps drinking water producers to allocate resources for risk reduction measures directed towards the most relevant type of risk (e.g. health risks, supply interruption, etc.). Additionally, CBA allows for comparison of risk reduction measures overarching several sectors, optimising the use of societal resources.

\section{Conclusions}

Based on the review of the health valuation methods and the results of the case study, the following main conclusions were drawn:
- Seven health valuation methods were identified: willingness to pay, cost of illness, cost of illness + disutility, value of a disability adjusted life year, value of a quality adjusted life year, societal value of a disability adjusted live year and societal value of a quality adjusted live year. The rank order of the risk mitigation alternatives with respect to their net present values may differ depending on the health valuation method.

- A low discount rate and a long time horizon favours mitigation alternatives with benefits that occur in the future.

- In CBA for decision support in the drinking water context, it is important to include all health benefit aspects. The most comprehensive currently available valuation methods to include all aspects of health benefits are the societal value of a quality adjusted life year or of a disability adjusted life year.

- If the choice of health valuation method is ambiguous, a sensitivity analysis of the health valuation methods should be performed in order to provide adequate decision support.

Acknowledgements Funding has been provided by the Swedish Water and Wastewater Association, through the project Risk-Based Decision Support for Safe Drinking Water (project 13-102). The research is part of DRICKS, a framework programme for drinking water research coordinated by the Chalmers University of Technology.

Open Access This article is distributed under the terms of the Creative Commons Attribution 4.0 International License (http://creativeco mmons.org/licenses/by/4.0/), which permits unrestricted use, distribution, and reproduction in any medium, provided you give appropriate credit to the original author(s) and the source, provide a link to the Creative Commons license, and indicate if changes were made.

\section{Appendix}

Reduction in probability of infection with each reference pathogen in each risk mitigation alternative is reported in Table 3.

The cost for one illness with each reference pathogen is reported in Table 4. 


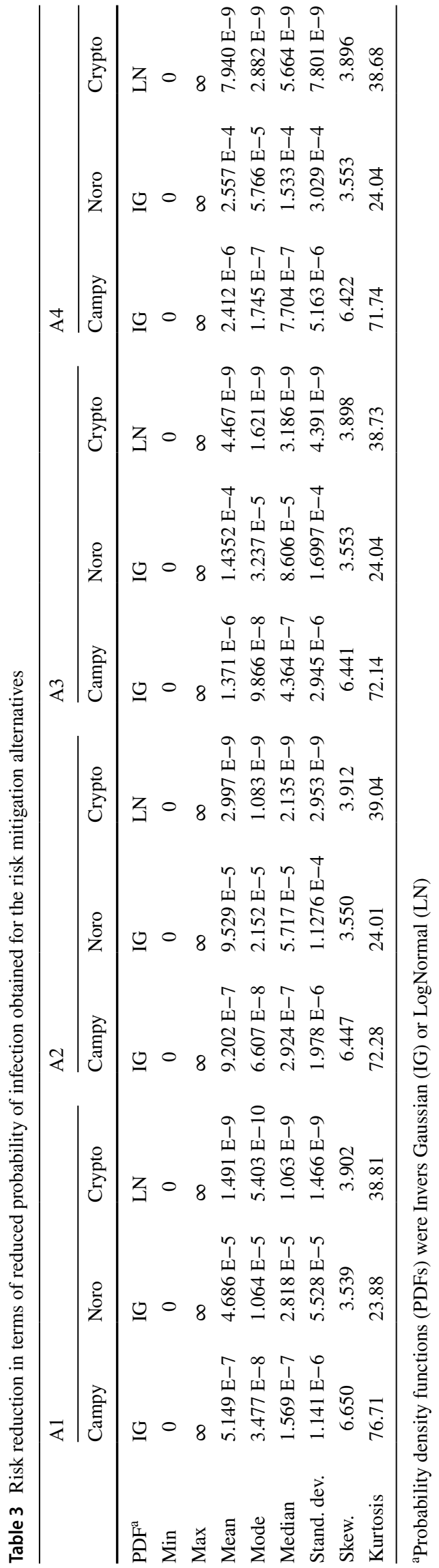

Table 4 Values used in the case study (reported in SEK) for the benefits of avoiding one illness with each reference pathogen for the different valuation methods

\begin{tabular}{lrrr}
\hline $\begin{array}{l}\text { Valuation } \\
\text { method }^{\mathrm{a}}\end{array}$ & Campylobacter & Norovirus & Cryptosporidium \\
\hline WTP & 499,800 & 29,220 & 111,400 \\
COI & 9586 & 4775 & 18,530 \\
COI+ & 30,540 & 6064 & 26,270 \\
VoD & 4497 & 982 & 3661 \\
VoQ & 11,850 & 679 & 2641 \\
SVoD & 5635 & 1230 & 4587 \\
SVoQ & 19,730 & 1131 & 4398 \\
\hline
\end{tabular}

${ }^{\mathrm{a}}$ Willingness to pay (WTP), cost of illness (COI), cost of illness and disutility (COI+), value of a DALY (VoD), value of a QALY (VoQ), societal value of a DALY (SVoD) and societal value of a QALY (SVoQ)

\section{References}

Abrahamsson JL, Ansker J, Heinicke G (2009) MRA: a model for Swedish water works. Swedish Water and Wastewater Association, Stockholm

Adamowicz W, Dupont D, Krupnick A, Zhang J (2011) Valuation of cancer and microbial disease risk reductions in municipal drinking water: an analysis of risk context using multiple valuation methods. J Environ Econ Manag 61:213-226. https://doi.org/10.1016/j. jeem.2010.10.003

Andersson H, Hammitt JK, Sundström K (2015) Willingness to pay and QALYs: what can we learn about valuing foodborne risk? J Agric Econ 66:727-752. https://doi.org/10.1111/1477-9552.12109

Andersson H, Hole AR, Svensson M (2016) Valuation of small and multiple health risks: a critical analysis of SP data applied to food and water safety. J Environ Econ Manag 75:41-53. https://doi. org/10.1016/j.jeem.2015.11.001

Batz M, Hoffmann S, Morris JG Jr (2014) Disease-outcome trees, EQ-5D scores, and estimated annual losses of quality-adjusted life years (QALYs) for 14 foodborne pathogens in the United States. Foodborne pathog Dis 11:395-402

Bergion V, Lindhe A, Sokolova E, Rosén L (2018) Risk-based costbenefit analysis for evaluating microbial risk mitigation in a drinking water system. Water Res 132:111-123. https://doi. org/10.1016/j.watres.2017.12.054

Birol E, Karousakis K, Koundouri P (2006) Using economic valuation techniques to inform water resources management: a survey and critical appraisal of available techniques and an application. Sci Total Environ 365:105-122

Boardman AE, Greenberg DH, Vining AR, Weimar DL (2011) Costbenefit analysis: concepts and practice. Prentice Hall, Upper Saddle River

Bobinac A, van Exel NJA, Rutten FFH, Brouwer WBF (2010) Willingness to pay for a quality-adjusted life-year: the individual perspective. Value Health 13:1046-1055. https://doi.org/10.111 1/j.1524-4733.2010.00781.x

Bobinac A, van Exel NJ, Rutten FF, Brouwer WB (2013) Valuing QALY gains by applying a societal perspective. Health Econ 22:1272-1281. https://doi.org/10.1002/hec.2879

Brent RJ (2011) An implicit price of a DALY for use in a cost-benefit analysis of ARVs. Appl Econ 43:1413-1421. https://doi. org/10.1080/00036840802600475 
Cookson R (2003) Willingness to pay methods in health care: a sceptical view. Health Econ 12:891-894. https://doi.org/10.1002/ hec. 847

Gyllensvärd H (2010) Cost-effectiveness of injury prevention: a systematic review of municipality based interventions. Cost Eff Resour Alloc 8:17. https://doi.org/10.1186/1478-7547-8-17

Haas CN, Rose JB, Gerba CP (2014) Quantitative microbial risk assessment, 2nd edn. Wiley, Hoboken

Hammitt JK, Haninger K (2017) Valuing nonfatal health risk as a function of illness severity and duration: Benefit transfer using QALYs. J Environ Econ Manag 82:17-38. https://doi. org/10.1016/j.jeem.2016.10.002

Haninger K, Hammitt JK (2011) Diminishing willingness to pay per quality-adjusted life year: valuing acute foodborne illness. Risk Anal 31:1363-1380

Hanley N, Barbier EB (2009) Pricing nature: cost-benefit analysis and environmental policy. Edward Elgar, Cheltenham

Hoffmann S, Batz MB, Morris JG (2012) Annual cost of illness and quality-adjusted life year losses in the United States due to 14 foodborne pathogens. J Food Prot 75:1292-1302. https://doi. org/10.4315/0362-028x.jfp-11-417

Hofstetter P, Hammitt JK (2002) Selecting human health metrics for environmental decision-support tools. Risk Anal 22:965-983

Hutton G (2001) Economic evaluation and priority setting in water and sanitation interventions. Water quality: guidelines, standard and health. IWA, World Health Organization, pp 333-359

Lindberg A, Lusua J, Nevhage B (2011) Cryptosporidium in Östersund during the winter 2010/2011: consequences and costs from an outbreak of a waterborne disease. Swedish Defence Research Agency, Stockholm

Lvovsky K, Huges G, Maddison D, Ostro B, Pearce D (2000) Environmental costs of fossil fuels. The World Bank, Washington, DC

Mangen MJJ, Havelaar AH, Bernsen RAJAM, Van Koningsveld R, De Wit GA (2005) The costs of human Campylobacter infections and sequelae in the Netherlands: a DALY and cost-of-illness approach. Acta Agric Scand Sect C 2:35-51. https://doi.org/10.1080/16507 540510033451

Mangen MJJ, Batz MB, Käsbohrer A, Hald T, Morris JG Jr, Taylor M, Havelaar AH (2010) Integrated approaches for the public health prioritization of foodborne and zoonotic pathogens. Risk Anal 30:782-797. https://doi.org/10.1111/j.1539-6924.2009.01291.x

Mauskopf JA, French MT (1991) Estimating the value of avoiding morbidity and mortality from foodborne illnesses. Risk Anal 11:619-631

Minor T, Lasher A, Klontz K, Brown B, Nardinelli C, Zorn D (2015) The per case and total annual costs of foodborne illness in the United States. Risk Anal 35:1125-1139. https://doi.org/10.1111/ risa. 12316

NBHW (2015) National guidelines for cardiac care, basis for health economics (appendix). National Board of Health and Welfare, Sweden

PHAS (2011) Outbreak of disease caused by drinking water in Sweden 1992-2011. Östersund

Polyzou E, Jones N, Evangelinos KI, Halvadakis CP (2011) Willingness to pay for drinking water quality improvement and the influence of social capital. J Socio-Econ 40:74-80. https://doi. org/10.1016/j.socec.2010.06.010

Ready R et al (2004) Benefit transfer in europe: how reliable are transfers between countries? Environ Resour Econ 29:67-82. https:// doi.org/10.1023/B:EARE.0000035441.37039.8a

Reed Johnson F, Fries EE, Spencer Banzhaf H (1997) Valuing morbidity: an integration of the willingness-to-pay and healthstatus index literatures. J Health Econ 16:641-665. https://doi. org/10.1016/S0167-6296(97)00012-X

Rice G, Heberling MT, Rothermich M, Wright JM, Murphy PA, Craun MF, Craun GF (2006) The role of disease burden measures in future estimates of endemic waterborne disease. J Water Health 4:187-199. https://doi.org/10.2166/wh.2006.023

Robinson LA, Hammitt JK, Chang AY, Resch S (2016) Understanding and improving the one and three times GDP per capita costeffectiveness thresholds. Health Policy Plan 32:141-145

Ryen L, Svensson M (2015) The willingness to pay for a quality adjusted life year: a review of the empirical literature. Health Econ 24:1289-1301. https://doi.org/10.1002/hec.3085

SBU (2014) Evaluation of methods in healthcare: a guidebook. Swedish Agency for Health Technology Assessment and Assessment of Social Services

Scharff RL (2012) Economic burden from health losses due to foodborne illness in the United States. J Food Prot 75:123-131. https ://doi.org/10.4315/0362-028x.jfp-11-058

Schijven JF, Teunis PF, Rutjes SA, Bouwknegt M, de Roda Husman AM (2011) QMRAspot: a tool for Quantitative Microbial Risk Assessment from surface water to potable water. Water Res 45:5564-5576. https://doi.org/10.1016/j.watres.2011.08.024

Seethaler R (1999) Health costs due to road traffic-related air pollution An impact assessment project of Austria, France and Switzerland. Studie im Auftrag der World Health Organization (WHO) Herausgeber Eidg Departement für Umwelt, Verkehr, Energie und Kommunikation (UVEK) Bestellnr 801

Shiroiwa T, Sung YK, Fukuda T, Lang HC, Bae SC, Tsutani K (2010) International survey on willingness-to-pay (WTP) for one additional QALY gained: what is the threshold of cost effectiveness? Health Econ 19:422-437. https://doi.org/10.1002/hec.1481

Smith RD, Richardson J (2005) Can we estimate the 'social' value of a QALY? Four core issues to resolve. Health Policy 74:77-84. https ://doi.org/10.1016/j.healthpol.2004.12.009

SNIER (2009) Climate adaption in Sweden: societal economic valuation of health effects. Swedish National Institute of Economic Research, Stockholm

STA (2016) Method and socioeconomical calculation values for the transport sector: ASEK 6.0. Swedish Transport Administration, Borlänge

Statistics Sweden (2018a) National Accounts, quarterly and annual estimates. Statistics Sweden. http://www.scb.se/hitta-statistik/stati stik-efter-amne/nationalrakenskaper/nationalrakenskaper/natio nalrakenskaper-kvartals-och-arsberakningar/. Accessed May 31 2018

Statistics Sweden (2018b) Population growth projections. Statistics Sweden. http://www.scb.se/Statistik/BE/BE0401/2016I60/BE040 1_2016I60_SM_BE18SM1601.pdf. Accessed June 252018

Statistics Sweden (2018c) Price calculator. Statistics Sweden. http:// www.scb.se/hitta-statistik/sverige-i-siffror/prisomraknaren/. Accessed June 212018

Sundström K (2018) Cost of illness for five major foodborne illnesses and sequelae in Sweden. Appl Health Econ Health Policy. https ://doi.org/10.1007/s40258-017-0369-z

Svensson M, Nilsson FOL, Arnberg K (2015) Reimbursement decisions for pharmaceuticals in Sweden: the impact of disease severity and cost effectiveness. PharmacoEconomics 33:1229-1236. https://doi.org/10.1007/s40273-015-0307-6

Sveriges Riksbank (2018) Annual average exchange rates. https://www. riksbank.se/sv/statistik/sok-rantor-valutakurser/arsgenomsnittvalutakurser $/ \mathrm{y}=2017 \& \mathrm{~m}=12 \& \mathrm{~s}=\mathrm{Comma} \& \mathrm{f}=\mathrm{y}$. Accessed June 212018

Van Houtven G, Powers J, Jessup A, Yang J-C (2006) Valuing avoided morbidity using meta-regression analysis: what can health status measures and QALYs tell us about WTP? Health Econ 15:775795. https://doi.org/10.1002/hec.1105

Viscusi WK, Huber J, Bell J (2012) Heterogeneity in values of morbidity risks from drinking water. Environ Resour Econ 52:23-48. https://doi.org/10.1007/s10640-011-9517-3 
Whitehead SJ, Ali S (2010) Health outcomes in economic evaluation: the QALY and utilities. Br Med Bull 96:5-21

WHO (2001) Macroeconomics and health: investing in health for economic development. World Health Organization, Geneva

WHO (2008) The global burden of disease: 2004 update. World Health Organization, Geneva

WHO (2016) Quantitative microbial risk assessment: application for water safety management, 2016th edn. World Health Organization, Geneva

WSP (2010) Socio-economic analysis of ultra filter installation at Lackarebäcks and Alelyckan drinking water treatmen plants (In swedish: "Samhällsekonomisk analys av installation av ultrafilter vid Lackarebäcks och Alelyckans vattenverk"). Stockholm

Publisher's Note Springer Nature remains neutral with regard to jurisdictional claims in published maps and institutional affiliations. 